\title{
Proton Pompa İnhibitörlerinin Kırık Oluşumuna Etkisi ve Bakıma Yansıması*
}

\author{
Seda AKUTAY** Özlem CEYHAN***
}

\section{$\ddot{O} z$}

Proton pompa inhibitörleri (PPİ) gastrointestinal sistem hastalıklarında ve nonsteroidal antiinflamatuar ilaçların gastrointestinal sistem üzerindeki yan etkilerini önlemek amacıyla kullanılan ilaçlardır. Ülkemizde yapılan çalışmalar yıllar içinde proton pompa inhibitörlerinin kullanımındaki artışı gözler önüne sermiştir. Tüm ilaçlarda olduğu gibi proton pompa inhibitörlerinin de kullanımıyla bazı istenmeyen etkiler gelişebilmektedir. Artmış kemik kırığı riski proton pompa inhibitörlerinin uzun dönem kullanımları ile ortaya çıkan yan etkiler arasında yer almaktadır. Proton pompa inhibitörlerinin kemik kırığına yol açma nedenleri ile ilgili pek çok teori ileri sürülmektedir. Son yıllarda yapılan meta-analiz ve sistematik derlemelerden ortaya çıkan sonuçlar kırığa zemin hazırladığını destekler nitelikte olup bir yıldan uzun süreli proton pompa inhibitörü kullananlarda kalça kırığı, vertebra kırığı, bilek ve ön kol kırığının proton pompa inhibitörü kullanmayanlara göre birkaç kat daha fazla olduğu yönündedir. Özellikle yaşlı ve kadınlarda kırık riskinin daha fazla olduğu bildirilmektedir. Bu derleme PPİ kullanımının oluşturduğu riskler açısından dikkat çekmesi ve bakımı planlamada yol gösterici olması amacı ile yazılmıştır.

Anahtar Kelimeler: İlaçla İlișkili Yan Etki, Kırıklar, Proton Pompa İnhibitörleri

\begin{abstract}
The Effect of Proton Pump Inhibitors on Fracture Formation and Reflection on Care

Proton pump inhibitors (PPI) are used in gastrointestinal system diseases and nonsteroidal anti-inflammatory drugs to prevent side effects of gastrointestinal system. Studies in our country have shown the increase in the use of proton pump inhibitors over the years. As it exists in all drugs, the use of proton pump inhibitors may cause some undesirable effects. These side effects can be considered in two groups as short and long term side effects. Increased risk of bone fracture is one of the side effects associated with the long-term use of proton pump inhibitors. A my riad of theories have been proposed regarding the causes of proton pump inhibitors leading to bone fracture. The results obtained from the meta-analysis and systematic reviews conducted in recent years support that they predispose to the fracture and suggest that hip fractures, vertebral fractures, wrist and forearm fractures are several times higher in those who use proton pump inhibitors for more than one year than those who do not use proton pump inhibitors.It is reported that the risk of fracture is higher especially in elderly and women. This review was written to draw attention to the risks posed by the use of PPI and to guide the planning of care.
\end{abstract}

Key Words: Drug related side effect, fractures, proton pump inhibitors

Geliş tarihi: 02.06.2020 Kabul tarihi: 08.12.2020

$\mathrm{J}$

ohn Edkins'in 1905 yılında gastrini keşfi; mide asit salgısını düzenleyen mekanizmaları ortaya çıkaracak çalışmaların yapılmasına, peptik ülser patogenezinin araştırılmasına ve tedavi yollarının aranmasına öncülük etmiştir $(1,2)$. Histamin-2 reseptör antagonistlerinin 1972 yılında, proton pompa inhibitörlerinin (PPI) ise 1989 yılında keşfiyle peptik ülser tedavisi hız kazanmıştır $(1,3)$. PPİ, gastrointestinal sistem hastalıklarını, üst gastrointestinal kanamalarını, antibiyotik ve nonsteroidal antiinflamatuar ilaçların gastrointestinal sistem üzerindeki yan etkilerini önlemek amacıyla kullanılan ilaçlardır (4). Tüm dünyada olduğu gibi Türkiye'de de yıllar içinde kullanımı giderek artmakta ve tedavi maliyeti ülke ekonomisine katlanarak yansımaktadır. Yapılan bir çalışmada Türkiye'de 2011 yılında toplam uygulanan bir aylık PPİ tedavi sayısı 35 milyon adet ve ortalama bir aylık tedavi maliyeti ise 484 milyon TL olarak bulunmuştur (5). PPI'ler dünyada antibiyotik ve statinlerden sonra en çok kullanılan üçüncü ilaç grubudur (3). Bu derleme PPİ kullanımının oluşturduğu riskler açısından dikkat çekmesi ve bakımı planlamada hemşirelere yol gösterici olması amacı ile yazılmıştır.

\section{Midenin Salgı İşlevi ve Proton Pompa İnhibitörleri}

Mide, tüm yüzeyini kaplayan mukus salgilayan hücrelere ek olarak gövde ve fundusunda yer alan paryetal hücreler ve antrumda bulunan pilor hücrelerinden oluşmaktadır. Paryetal hücrelerden $\mathrm{pH}$ 'ı yaklaşık 0,8 olan oldukça asidik hidroklorik asit salgılanır. Paryetal hücrelerden asit salgısının oluşması için temel uyarıcılar histamin ve gastrindir. Histamin, midedeki paryetal hücrelerin yakınlarında bulunan enterokromafin hücrelerinden salgılanır. Enterokromafin hücrelerinden histamin salgısının uyarılması ise gastrin hormonuna bağlıdır. Gastrin, protein sindirimde görevli olan, pilorda bulunan G hücrelerinden salgılanan bir hormondur. Yiyecekler mideye geldiğinde salgılanır ve histaminle birlikte hızlı bir şekilde hidroklorik asit salgısını uyarır. Mide asit salgısı aşırı artınca da gastrin salgısı negatif feedback mekanizması ile inhibe olur. Mide asit salgısının oluşmasında görevli bir diğer faktör paryetal hücrelerdeki proton pompaları olarak bilinen hidrojen-potasyum pompası $\left(\mathrm{H}^{+}-\mathrm{K}^{+}\right.$ATPaz $)$dır. Paryetal hücre sitoplazmasındaki su, $\mathrm{H}^{+}$ve $\mathrm{OH}^{-}$iyonlarına ayrışır. Daha sonra $\mathrm{H}^{+}-\mathrm{K}^{+}$ATPaz pompası ile paryetal hücrenin salgı kanalındaki potasyum iyonuyla yer değiştirerek hücre dışına pompalanır. Hücre içine kan yoluyla gelen $\mathrm{CO}_{2}$, karbonik anhidraz enzimiyle $\mathrm{HCO}_{3}$ oluşturur. Oluşan $\mathrm{HCO}_{3}$ hücre dışındaki $\mathrm{Cl}^{-}$iyonu ile yer değiştirerek hücre dışına taşınır. Hücre içine giren $\mathrm{Cl}^{-}$iyonu klor kanalları yoluyla kanala taşınır ve kanalda bulunan $\mathrm{H}^{+}$ile birlikte kuvvetli hidroklorik asiti oluşturur $(3,6)$ (Şekil 1).

* Bu derleme, 1-3 Kasım 2019 tarihleri arasında Gaziantep’te yapılan 1.Uluslararası Hemşirelik Bakımı ve Araştırma Kongresi’nde poster bildiri olarak sunulmuștur.**Sorumlu yazar, Araștırma Görevlisi, Erciyes Üniversitesi Sağlık Bilimleri Fakültesi Cerrahi Hastalıkları Hemșireliği Anabilim Dalı, Kayseri Orcid: https://orcid.org/0000-0002-2843-8392 E posta: sedaakutay@erciyes.edu.tr Tel: 0352 2076666- 28572 *** Doçent Doktor, Erciyes Üniversitesi Sağlık Bilimleri Fakültesi İç Hastalıkları Hemşireliği Anabilim Dalı, Kayseri Orcid: https://orcid.org/0000-0002-1869-8713 


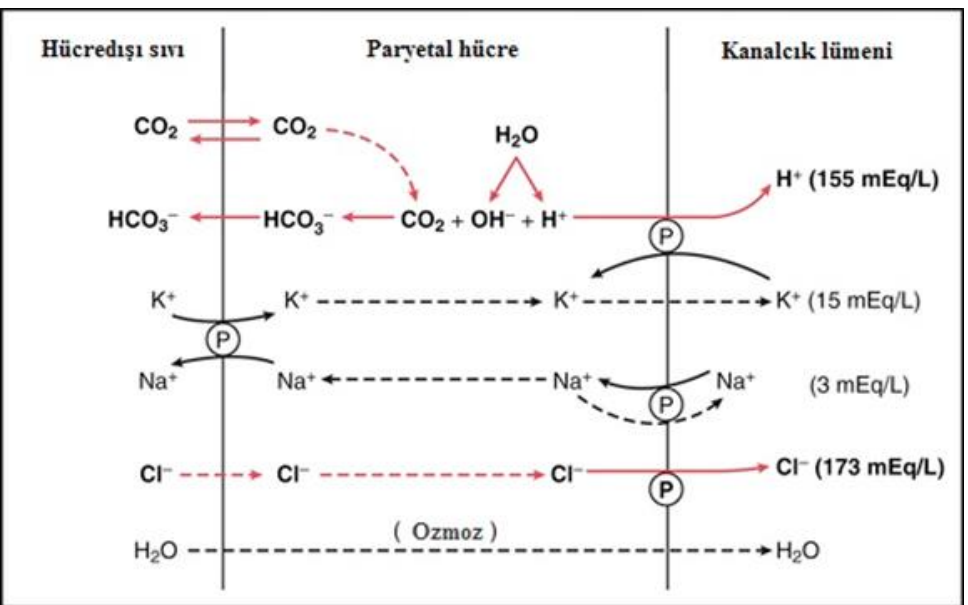

\section{Şekil 1.Hidroklorik Asit Salgısı Ana Mekanizması (7)}

PPI'ler oral yoldan alındıklarında ince bağırsakta açılacak şekilde üretilmiş olup, buradan emilerek karaciğere taşınır. Karaciğerde metabolize edilir ve sistemik dolaşımla paryetal hücre kanal lümenine geçer, konsantre hale gelir ve $\mathrm{H}^{+}$iyonu ile aktif forma geçer. Aktifleşen PPI'ler $\mathrm{H}^{+}-\mathrm{K}^{+}$ATPaz pompasına geri dönüşümsüz olarak bağlanarak pompayı inhibe eder. Böylece mide asit sekresyonunu \%99 oranında inhibe etmiş olur $(4,7)$.

\section{Proton Pompa İnhibitörlerinin Yan Etkileri}

Proton pompa inhibitörleri, peptik ülser, gastroözefageal reflü, dispepsi, gastrointestinal sistem kanamaları ve bu hastalıkların tedavisinde etkili olan ayrıca nonsteroidal antiinflamatuar, antitrombotik, antibiyotik ve kortikosteroid gibi ilaçların mide üzerinde oluşturduğu olumsuz etkileri ortadan kaldırmak amacıyla sıklıkla kullanılan ilaçlardır (8). Özellikle hastaneye yatan yaşlı hastalarda PPİ'lerin tedavi edici ya da stres ülseri için profilaktik amaçlı reçete edildiği fakat hastaneden taburcu edilmeden önce tedaviye son verilmediği bu yüzden uzun süreli aşırı kullanımlar olduğu bilinmektedir (9). PPİ'ler, asite bağlı üst gastrointestinal hastalıklarda etkili ve iyi tolere edilebilen ilaçlar olmalarına rağmen, kısa süreli kullanımları \%1-3 oranında baş ağrısı, karın ağrısı, diyare, konstipasyon, baş dönmesi, bulantı gibi hafif yan etkilere neden olabilmektedir (10,11). PPI’lerin uzun süreli kullanımları ise mide asit sekresyonunun inhibisyonuna bağlı hipoklorhidi ve hipergastrinemiye bağlı enterik enfeksiyonlar, toplum kökenli pnömoni, nöroendokrin hiperplazi/gastrik nöroendokrin tümör, vitamin ve mineral absorbsiyon ve metabolizmasında bozulma ve kemik kırı̆̆ı riskini beraberinde getirmektedir $(3,7,10,12)$.

\section{Proton Pompa İnhibitörleri ve Kırık Oluşumu}

Artmış kemik kırığı riski PPI’lerin uzun dönem kullanımları ile ortaya çıkan yan etkiler arasında yer almaktadır. Amerikan Gıda ve İlaç Dairesi’nin 2011 yılında yayınladığı uyarıda kısa süreli ve düşük dozlarda PPİ kullanımının kırık oluşumu açısından risk oluşturmadığı ancak yüksek doz ve uzun süre kullanımının el bileği, kalça ve omurgada kırık oluşum riskini artıracağı sonucuna varılmıştır (13). On sekiz gözlemsel çalışmanın incelendiği bir meta-analizde, bir yıldan uzun süreli PPİ kullanımının vücudun herhangi bir bölgesinde kırık riskini \%33 artırdığı, kalça kırı̆̆1 riskini \%26 ve omurga kırı̆̆1 riskini \%58 artırdığ1 ortaya konulmuştur (14). Nassar ve Richter tarafından 2018 yılında yayınlanan bir meta-analizde uzun süreli PPİ kullanımının özellikle kalça ve vertebra kırıklarını artırdığı saptanmış, bunu önlemek için sürekli PPİ kullanan hastalarda günlük kalsiyum ve D vitamini alımının sağlanması gerektiği belirtilmiştir (15). PPI’lerin kırık oluşturma riskleri çocuk, genç, yaşlı, menopoz sonrası kadınlar gibi pek çok grupta araştırılmıştır (16-19). Yetişkinlerin aksine çocuklarda kırık riskinin doza bağlı olmadığı, çocuklarda en sık el ve el bileği kırıkları, genç yetişkinlerde ise el ve ayak kırıklarına rastlandığı tespit edilmiştir (16). Menopoz sonrası kadınlarla yapılan çalışmalarda bir yıldan uzun süre PPİ alan kadınlarda kırık riskinde artış olduğu ve bu kişilerde B12 vitamininin anlamlı derecede düşük olduğu görülmüştür (17,20-22). Yaşlılarda PPİ'lerin kırık oluşturma risklerinin araştırıldığı bir çalışmada ise düşmelerle bağlantılı olarak torasik ve pelvik kemiklerde kırık oluşturduğu bildirilmiştir (23).

Proton pompa inhibitörlerinin kemik kırığına yol açma nedenleri ile ilgili pek çok teori ileri sürülmektedir. Bu teoriler proton pompa inhibitörlerinin gastrik asit salgısını inhibe ederek bağırsaklardan kalsiyum emilimini azalttığı, B12 vitamini, folik asit, riboflavin absorbsiyonunu inhibe edip homosistein düzeyini azalttığ1, osteoklastlarda bulunan proton pompalarını da inhibe ederek kırığa zemin hazırladığı şeklindedir (3,10,24-26). Osteoklastlarla ilgili teorinin aksini savunarak PPİ kullanımının kırık riskini artırmayacağı, aksine kemik rezorpsiyonunu azaltarak kemik dansitesini artıracağı ve osteoporozu teorik olarak önleyeceği ifade edilmektedir (4). Konuyla ilgili meta-analiz ve sistematik derlemelerden ortaya çıkan sonuçlar kırık riskini artıracağ1 yönündeki teorileri destekler nitelikte olup bir yıldan uzun süreli PPİ kullananlarda kalça kırığ1, vertebra kırığ1, bilek ve ön kol kırığının PPİ kullanmayanlara göre daha fazla olduğu yönündedir $(14,15,27-30)$. Çeşitli hayvan modellerinden ve kronik atrofik gastritli hastalardan elde edilen bulgular, mide hipoasiditesinin kemik metabolizmasını olumsuz etkilediğini öne sürse de, bunun aksine randomize bir çalışmadan elde edilen son veriler PPİ'lerin kırık riskini artırmadığını öne sürmektedir (31). Epidemiyolojik çalışmalarda gözlenen doza bağlı olarak PPİ kullanımına bağlı artmış kemik kırı̆̆ı riski, komorbiditenin artması ve düşme riski ile ilişkili faktörlerle açıklanabilmektedir (32).

Proton pompa inhibitörlerinin kırık oluşturma nedenleri temelde iki ana faktöre bağlanmaktadır. Bunlar hipergastrinemi ve hipoklorhidridir (19). PPİ'lerin paryetal hücrelerdeki proton pompalarına geri dönüşümsüz olarak bağlanması sonucu hidrojen iyon konsantrasyonu azalır ve midenin pH'ı bazikleşmeye başlar. G hücreleri, azalan hidrojen iyon konsantrasyonunu artırmak için paryetal hücreleri uyarmak amacıyla gastrin salgılar. Hipergastrinemi, enterokromafin hücrelerinde hiperplaziye yol açarak histamin salgısında da artışa neden olur. Normal koşullarda \%7 olan hücre içi histamin miktarı gastrinin uyarmasıyla \%24'e 
Derleme

kadar yükselir (33). Histamin kemik metabolizmasında etkili bir nörotransmitter olup osteoklast sayısının artmasına neden olduğu düşünülmektedir (34). Fakat yüksek histamin konsantrasyonunun kemikler üzerine etkisini gösteren yeterli sayıda çalışma yoktur (19).

Hipergastrineminin aynı zamanda paratiroid hormonunda (PTH) artışla da ilişkili olduğu belirlenmiştir. Beş hafta PPI tedavisi alan tavuklarda paratiroid bezinde hiperplazi ve hipertrofi geliştiği ve PTH artışıla bağlantılı olarak kemik yoğunluğunda azalma bildirilmiştir $(30,35)$. İnsanlarda yapılan çalışmalarda PPİ kullanımı ile PTH seviyesinde artma ve buna bağlı serum kalsiyum düzeylerinde düşme olduğu belirlenmiştir (36). Kadın hastalarla yapılan bir çalışmada 14 gün PPİ tedavisi alımının kalsiyum karbonat emilimini ortalama \%41 oranında azalttığı bulunmuştur (37). Bozulmuş kalsiyum emilimi, osteoklastik kemik rezorpsiyonunu kompanse etmek amaciyla sekonder hiperparatiroidizme de neden olmaktadır (38).

Kalsiyum tuzlarının ince bağırsaktan emilimi pH'a bağlıdır. Gastrointestinal kanaldaki asidik ortam kalsiyum tuzlarından iyonize hale gelen kalsiyumun salınımını kolaylaştırmaktadır (8). Böylece PPİ'lere bağlı asit miktarındaki azalma kalsiyum salınımını da etkilemektedir. Fareler üzerinde yapılan deneysel bir çalışmada midedeki paryetal hücrelerinin östrojen sekresyonunda güçlü bir etkiye sahip olduğu belirlenmiştir. Östrojenin etkisiyle ghrelin yapımı uyarılır ve ghrelin osteoblastları uyararak kemik oluşumunu arttırmaktadır (39). Vestergaard ve arkadaşlarının yaptıkları bir çalışmada (n=373.62) PPİ kullanımının kırık riskinde küçük bir artmaya yol açtığı, $\mathrm{H}_{2}$-reseptör antagonisti kullanımının ise kırık riskinin azalması ile ilişkili olduğu tespit edilmiştir (40,41). Targownik ve arkadaşlarının yaptıkları çalışmadan elde edilen sonuçlarda ise altı yıldan kısa süreli PPİ kullanımının kırık riskinde bir artışa yol açmadığı, yedi yıl veya daha uzun süreli PPİ kullanımının osteoporotik kırık riski ile ilişkili olduğu bulunmuştur (42). Bunların aksini ispatlayan ve başka bir risk faktörü olmayan hastalarda, PPİ kullanımı ile kırık riski arasında ilişki olmadığını savunan araştırmalar da vardır $(43,44)$.

\section{Proton Pompa İnhibitörü Kullanımı ve Hemşirelik Bakımı}

Toplumda çok yaygın olarak kullanılan PPİ türündeki ilaçların sadece gereken durumlarda ve yeterli sürelerde kullanılmaları önemlidir. Özellikle osteoporoza yatkın olan hastalarda uzun süreli PPİ kullanımı olacaksa; $\mathrm{Ca}$, Mg ve D vitamini seviyelerine dikkat edilmeli ve gerekiyorsa bu mineral ve vitaminler takviye edilmeli ve bu konuda hasta bilgilendirilmelidir. Ayrica bu kişilerde aralıklı PPİ tedavisi bir seçenek olarak düşünülmelidir.

Hastalara bütüncül bakım veren hemşirelerin sadece mevcut hastalık hakkında değil hastanın hastalıkları nedeniyle kullandığı tedavi planında yer alan ilaçların yan etkileri konusunda da farkındalıkları yüksek olmalıdır. PPI’'ler hastaneye yatan hastaların tedavi planlarında sıklıkla yer alan ve hemşirelerin çok sık karşılaştıkları bir ilaç grubudur. Bu ilaçların pek çok yan etkileri bulunmakla birlikte özellikle ek başka risk faktörleri de olan hastalarda kırık oluşumuna zemin hazırladığ bakımda buna yönelik planlanmalar yapılmalıdır (23).

Uzun süreli PPİ kullanımı olan hastaların bakımında özellikle düşme riski dikkatle değerlendirilmeli, kırık oluşum riski ve diğer yan etkileri de göz önüne alınarak bu kişilere travma riski açısından gereken hemşirelik bakımı sağlanmalıdır. Ayrıca hasta ve ailesine düşme ve kırık oluşumu riski açısından ve kemik mineral yoğunluğu ve D vitamini ölçümlerini düzenli aralıklarla yaptırmalarının önemi konusunda eğitimler verilmelidir (38). Bu konuda ülkemizde bakım sorumluluğu, klinikte ve ev ziyaretleri ile alanda aktif hizmet veren ortopedi, geriatri ve evde bakım hemşirelerine düşmektedir. Hemşireler özellikle bir yıldan uzun süreli PPİ kullanımı olan, kronik hastalığa sahip, yaşlı ve kadın hastaların bakımları esnasında beslenme, aktivite, iletişim, görme ve bilişsel durum açısından bireyleri değerlendirmeli, bakım vermeli ve takip edilmelerini sağlamalıdır (45). Evde ve kurumda bakım esnasında, yaşanılan ortam ve çevresel faktörlerden kaynaklanan kırık risklerinin değerlendirilmesi ve önlenmesine yönelik girişimlerin planlanması, özellikle yalnız yaşayan yaşlı hastaların bakımlarının bu yönden daha dikkatli planlanması gerekmektedir. Ayrıca toplumu bu konularda bilgilendirme aktivitelerinin yapılması da hemşirelerin sorumlulukları arasında olmalıdır. Yurt dışında fraktür liyezon hizmetleri bulunmaktadır. Fraktür liyezon hizmetleri temelde riskli hastalarda kırık oluşumunu en aza indirmeyi amaçlamaktadır. Fraktür liyezon hizmetleri, 1990'l1 yılların sonunda gündeme gelmiştir ve son yıllarda önemi giderek artmaktadır (46). Ülkemizde henüz fraktür liyezon hemşireliğiyle ilgili bir oluşum bulunmamakla birlikte, önemi gittikçe artan bu hizmetin travma ve ilaç kullanımına bağlı olarak gelişen kırıkları önlemeye yönelik faaliyetlerin başlatılmasında yararlı olacağı düşünülmektedir.

Sonuç olarak, hastalık ve tedavilere sekonder olarak gelişen kırıkların morbidite ve mortaliteyi olumsuz etkilemesi ve kırık riski yüksek olan hastaların çeşitli nedenlerle tedavi başarılarının düşük olması ve kırık oluşumu durumunda tedavi ve bakım maliyetinin yüksek oluşu nedeniyle bir risk faktörü olan PPİ'lerin uzun süreli kullanımlarının gerekliliği sorgulanmalı, uzun süre kullanan hastalar kırık açısından değerlendirilmeli ve takipleri yapılmalıdır. Bunun için ilaç uygulamasından ve bakımdan sorumlu olan hemşirelerin hasta öykülerinde bu ilaç kullanımını sorgulamaları ve kullananlarda gerekli bakım ve izlemleri yapmaları önemlidir. Bu konuya hemşirelerin dikkatini çekmek için eğitimlerin verilmesi ve PPİ kullanımı olan hastalara verilen hemşirelik bakımı ile kırık oluşumu arasındaki ilişkinin incelendiği çalışmaların yapılması önerilebilir.

Çıkar çatışması: Yazarlar arasında herhangi bir çıkar çatışması yoktur. Ayrıca sorumlu olduğumuz araştırmada herhangi bir firma ile çıkar ilişkisi de bulunmamaktadır. Yazarların tümü çalışmanın tamamına katkı sağlamış ve son halini onaylamıştır.

\section{Bilgilendirme}

Araştırmacılar arasında herhangi bir çıkar çatışması bulunmamaktadır. Yazarların tümü çalışmanın tamamına katkı sağlamış ve son halini onaylamıştır

\section{Kaynaklar}

1. Alam G. Proton pump inhibitors: present and future a review. Int J Pharm Res Dev 2012;4:119-131. Available at: http://ijprd.com/April_12_.Issue.html. Accessed Dec 18, 2019

2. Modlin IM, Sachs G, Wright N, Kidd M. Edkins and a century of acid suppression. Digestion 2005;72:129-145. https://doi.org/10.1159/000088368 
Derleme

3. Uygun A. Uzun süre proton pompa inhibitörleri (PPI) kullanılacaksa, hangi PPI tercih edilmelidir? Nelere dikkat edilmelidir? Güncel Gastroenteroloji 2012;17:46-58. Erişim adresi: http://guncel.tgv.org.tr/journal/46/pdf/100126.pdf. Erişim tarihi 18 Aralık 2019

4. Özden A. Proton pompa inhibitörleri ve kullanım güvenirliği. Güncel Gastroenteroloji 2013;17:179-201. Erişim adresi: http://guncel.tgv.org.tr/journal/46/pdf/100126.pdf. Erişim tarihi 18 Aralık 2019

5. Bilgener E. Türkiye'de 2006-2011 yıllarında proton pompası inhibitörleri tüketiminin bütçeye etkisi. Ankara Ecz Fak Derg 2018;42:23-31. https://doi.org/10.1501/Eczfak_0000000604

6. Hall JE. Sindirim kanalının salgı işlevleri. In: Çağlayan Yeğen B. editor. Guyton ve Hall Tıbbi Fizyoloji, 12th ed. İstanbul, Nobel Tip Kitabevleri 2013:777-779.

7. Özdemir A, Okuroğlu N. Uzun süreli proton pompa inhibitörü kullanımı ve komplikasyonları. Boğaziçi Tıp Derg 2015;2:3542.

8. Scarpignato C, Gatta L, Zullo A, Blandizzi C, for the SIF-AIGO-FIMMG Group. Effective and safe proton pump inhibitor therapy in acid-related diseases-a position paper addressing benefits and potential harms of acid suppression. BMC Medicine 2016;14:179. http://dx.doi.org/10.1186/s12916-016-0718-z

9. Ksiadzyna D, Szelag A, Paradowski L. Overuse of proton pump inhibitors. Pol Arch Med Wewn 2015;125:289-298. http://dx.doi.org/10.20452/pamw.2790

10. Çelikbilek M, Doğan S, Akyol L, Yücesoy M. Proton pompa inhibitörlerinin yan etkileri. Bozok Tıp Derg 2013;1:49-52.

11. Sivri B. Proton pompa inhibitörleri: optimum proton pompa inhibitörü kullanımı nasıl olmalıdır ? İç Hast Derg 2013;20:107111.

12. Kayhan Koçak FÖ, Sahutoğlu S, Gökdemir B, Saraç ZF, Şahin S, Akçiçek SF. Uzun süreli proton pompa inhibitörü kullanımına sekonder gastrik nöroendokrin hiperplazi. Ege Tıp Derg 2018;57:244-246. https://doi.org/10.19161/etd.416055

13. FDA Drug Safety Communication: possible increased risk of fractures of the hip, wrist, and spine with the use of proton pump inhibitors FDA. Available at: https://www.fda.gov/drugs/postmarket-drug-safety-information-patients-andproviders/fda-drug-safety-communication-possible-increased-risk-fractures-hip-wrist-and-spine-use-proton-pump 2017. Accessed Dec 14, 2019

14. Zhou B, Huang Y, Li H, Sun W, Liu J. Proton-pump inhibitors and risk of fractures: an update meta-analysis. Osteoporos Int. 2016;27(1):339-47. https://doi.org/10.1007/s00198-015-3365-X

15. Nassar Y, Richter S. Proton-pump Inhibitor Use and Fracture Risk: An Updated Systematic Review and Meta-analysis. J Bone Metab. 2018;25(3):141-51. https://doi.org/10.11005/jbm.2018.25.3.141

16. Freedberg DE, Haynes K, Denburg MR, et al. Use of proton pump inhibitors is associated with fractures in young adults: a population-based study. Osteoporos Int 2015;26:2501-2507. https://doi.org/10.1007/s00198-015-3168-0

17. Lewis JR, Barre D, Zhu K, et al. Long-term proton pump inhibitor therapy and falls and fractures in elderly women: a prospective cohort study. J Bone Miner Res 2014;29:2489-2497. https://doi.org/10.1002/jbmr.2279

18. Reyes C, Formiga F, Coderch M, et al. Use of proton pump inhibitors and risk of fragility hip fracture in a Mediterranean region. Bone 2013;52:557-561. https://doi.org/10.1016/j.bone.2012.09.028

19. Thong BKS, Ima Nirwana S, Chin KY. Proton pump inhibitors and fracture risk: a review of current evidence and mechanisms involved. Int J Environ Res Public Health 2019;16:1571. https://doi.org/10.3390/ijerph16091571

20. Moberg LME, Nilsson PM, Samsioe G, Borgfeldt C. Use of Proton Pump İnhibitors (PPI) and history of earlier fracture are independent risk factors for fracture in postmenopausal women the WHILA study. Maturitas 2014;78:310-315. https://doi.org/10.1016/j.maturitas.2014.05.019

21. van der Hoorn MMC, Tett SE, de Vries OJ, Dobson AJ, Peeters GMEEG. The effect of dose and type of proton pump inhibitor use on risk of fractures and osteoporosis treatment in older Australian women: a prospective cohort study. Bone 2015;81:675-682. https://doi.org/10.1016/j.bone.2015.08.024

22. Kim JJ, Jang EJ, Park J, Soon H, Id S. Association between proton pump inhibitor use and risk of fracture : A populationbased case-control study. PLoS One.2020;15(7):1-13. http://doi.org/10.1371/journal.pone.0235163

23. Wang L, Li M, Cao Y, et al. Proton pump inhibitors and the risk for fracture at specific sites: data mining of the FDA adverse event reporting system. Sci Rep 2017;7:1-9. https://doi.org/10.1038/s41598-017-05552-1

24. Fusaro M, D’Arrigo G, Pitino A, et al. Increased risk of bone fractures in hemodialysis patients treated with proton pump inhibitors in real world: results from the Dialysis Outcomes and Practice Patterns Study (DOPPS). J Bone Miner Res 2019;34:2238-2245. https://doi.org/10.1002/jbmr.3842

25. Farina C, Gagliardi S. Selective Inhibition of Osteoclast Vacuolar H+-ATPase. Curr Pharm Des. 2002;8: $2033-48$.

26. Sahara T, Itoh K, Debari K, Sasaki T. Specific Biological Functions of Vacuolar-Type H+-ATPase and Lysosomal Cysteine Proteinase, Cathepsin K, in Osteoclasts. Anat Rec. 2003;161:152-61. https://doi.org/10.1002/ar.a.10020

27. Khalili H, Huang ES, Jacobson BC, Camargo CA, Feskanich D, Chan AT. Use of proton pump inhibitors and risk of hip fracture in relation to dietary and lifestyle factors: a prospective cohort study. BMJ 2012;344:e372. https://doi.org/10.1136/bmj.e372

28. Ngamruengphong S, Leontiadis GI, Radhi S, Dentino A, Nugent K. Proton pump inhibitors and risk of fracture: a systematic review and meta-analysis of observational studies. Am J Gastroenterol 2011;106:1209-1218. http://doi.org/10.1038/ajg.2011.113

29. Yang SD, Chen Q, Wei HK, Zhang F, Yang DL, Shen Y, et al. Bone fracture and the interaction between bisphosphonates and proton pump inhibitors: A meta-analysis. Int J Clin Exp Med. 2015;8(4):4899-910.

30. Kwok CS, Yeong JKY, Loke YK. Meta-analysis: Risk of fractures with acid-suppressing medication. Bone. 2011;48(4):76876. http://doi.org/10.1016/j.bone.2010.12.015 
Derleme

31. Moayyedi P, Eikelboom JW, Bosch J, Connolly SJ, Dyal L, Shestakovska O, et al. Safety of Proton Pump Inhibitors Based on a Large, Multi-Year, Randomized Trial of Patients Receiving Rivaroxaban or Aspirin. Gastroenterology. 2019;157:68291. http://doi.org/ 10.1053/j.gastro.2019.05.056

32. Fossmark R, Martinsen TC, Waldum HL. Adverse Effects of Proton Pump Inhibitors — Evidence and Plausibility. International Journal of Molecular Sciences. 2019;20(5203). http://doi.org/10.3390/ijms20205203

33. Yokota T, Matsui H, Matsuura B, Maeyama K, Onji M. Direct effects of proton pump inhibitors on histamine release from rat enterochromaffin-like cells. Eur J Pharmacol 2003;481:233-240. https://doi.org/10.1016/j.ejphar.2003.09.011

34. Biosse-Duplan M, Baroukh B, Dy M, De Vernejoul MC, Saffar JL. Histamine promotes osteoclastogenesis through the differential expression of histamine receptors on osteoclasts and osteoblasts. Am J Pathol 2009;174:1426-1434. https://doi.org/10.2353/ajpath.2009.080871

35. Gagnemo-Persson R, Samuelsson A, Håkanson R, Persson P. Chicken parathyroid hormone gene expression in response to gastrin, omeprazole, ergocalciferol, and restricted food intake. Calcif Tissue Int 1997;61:210-215. https://doi.org/10.1007/s002239900325

36. Hinson AM, Wilkerson BM, Rothman-Fitts I, Riggs AT, Stack BC, Bodenner DL. Hyperparathyroidism associated with long-term proton pump inhibitors independent of concurrent bisphosphonate therapy in elderly adults. J Am Geriatr Soc 2015;63:2070-2073. https://doi.org/10.1111/jgs.13661

37. O’Connell MB, Madden DM, Murray AM, Heaney RP, Kerzner LJ. Effects of proton pump inhibitors on calcium carbonate absorption in women: a randomized crossover trial. Am J Med 2005;118:778-781. https://doi.org/10.1016/j.amjmed.2005.02.007

38. Yang YX, Lewis JD, Epstein S, Metz DC. Long-term proton pump inhibitor therapy and risk of hip fracture. JAMA 2006;296:2947-2953. https://doi.org/10.1001/jama.296.24.2947

39. Sakata I, Tanaka T, Yamazaki M, Tanizaki T, Zheng Z, Sakai T. Gastric estrogen directly induces ghrelin expression and production in the rat stomach. J Endocrinol 2006;190:749-757. https://doi.org/10.1677/joe.1.06808

40. Vestergaard P, Rejnmark L, Mosekilde L. Proton pump inhibitors, histamine H2 receptor antagonists, and other antacid medications and the risk of fracture. 2006;79:76-83. https://doi.org/10.1007/s00223-006-0021-7

41. Fedida B, Schermann H, Ankory R, et al. Fracture risk of young adults receiving proton-pump inhibitors and H2-receptor antagonists. Int J Clin Pract 2019;73:e13339. https://doi.org/10.1111/ijcp.13339

42. Targownik LE, Lix LM, Leung S, Leslie WD. Proton-Pump inhibitor use is not associated with osteoporosis or accelerated bone mineral density loss. Gastroenterology 2010;138:896-904. http://doi.org/10.1053/j.gastro.2009.11.014

43. Hoff M, Skovlund E, Skurtveiet S. et al. Proton pump inhibitors and fracture risk. The HUNT study, Norway. Osteoporos Int 2020;31:109-118. https://doi.org/10.1007/s00198-019-05206-0

44. Targownik LE, Goertzen AL, Luo Y, Leslie WD. Long-term proton pump inhibitor use is not associated with changes in bone strength and structure. Am J Gastroenterol 2017;112:95-10. https://doi.org/10.1038/ajg.2016.481

45. Yüksel S, Ülker S. Kalça Kırıklı Hastalarda Bakımın Değerlendirilmesi : Prospektif Bir Çalışma. JAREN. 2018;4(2):65-74. https://doi.org/10.5222/jaren.2018.065

46. Demir SG, Kalkan ND, Taştan S. Ortopedi ve Travmatoloji hemşirelerinin değişen ve gelişen rolü: fraktür liyezon hemşireliği. Gazi Üniversitesi Sağl1k Bilim Derg 2018;3:53-62. 